\title{
Too Many Cooks May Spoil the First Book-and Jeopardize the Author's Career: Potential Pitfalls of Book Workshops
}

Kurt Weyland, University of Texas at Austin

ABSTRACT Book workshops are widely regarded as yielding important benefits for junior scholars; therefore, these intensive feedback sessions have proliferated in recent years. However, closer consideration suggests some important notes of caution. A wealth of additional suggestions does not necessarily improve a post-dissertation manuscript; instead, comments and criticisms advanced by senior experts may induce young authors to back away from or tone down innovative ideas or to address numerous additional factors and conditions, which can make their theory unwieldy and complicated. More important than the potential pitfalls for the first book itself are the heavy opportunity costs created by book workshops, which can jeopardize a junior colleague's career advancement. After all, the substantial revisions arising from these feedback sessions take time away from article production and the design and initial research for a second major project. In these ways, overinvestment in the first book can hurt a young scholar's chances at tenure time.

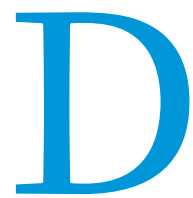

uring the past decade, book workshops have become de rigueur for young scholars. Generous postdoc appointments include funds for a book workshop, which is automatically assumed to be very helpful for turning a dissertation into a book from a highly ranked university press. It seems patently obvious that additional feedback can only strengthen a work of scholarship and, in this way, boost the career of a freshly minted $\mathrm{PhD}$. Who would want to look a gift horse in the mouth or politely decline the whole offer?

However, on closer inspection, a book workshop can have real downsides and hinder a young academic's career advancement. After all, without vetting their manuscripts through a book workshop, numerous former PhD students have in recent years managed to place their more or less revised dissertations with leading university presses. Other young scholars, by contrast, did organize book workshops yet ended up doing less well. Sometimes the wealth of comments received from several experts induced these authors to address a variety of additional, more tangential issues in the manuscript, making the overarching theory highly complex and the presentation of the argument difficult to follow. Frustratingly, the review process then required a good deal of renewed streamlining to restore the earlier coherence. In other cases, a

Kurt Weyland is Mike Hogg Professor in Liberal Arts in the department of government at the University of Texas at Austin. He can be reached at kweyland@austin.utexas.edu. freshly minted PhD can face an external expert who is unusually critical of the main argument at the daylong feedback session or participants who advance an overabundance of constructive suggestions. The beneficiaries (?) of all of these comments may take a long time to make the corresponding revisions, if they do not become bogged down or discouraged completely...

These divergent types of experiences suggest the importance of thinking about the potential pitfalls of book workshops and carefully assessing their likely benefits and costs-the task of this article. Indeed, my own participant observations and numerous conversations with young and older colleagues and with editors of Cambridge University Press and Princeton University Press indicate that a book workshop can be a mixed blessing. On the one hand, there certainly is the promise of significant benefits. The ample comments provided by the participating experts, on balance, often do improve the quality of the book that a junior scholar sooner or later publishes.

On the other hand, book workshops also can pose problems and risks for the book itself and especially for the author's career. The additional input from various sources may dilute the overarching argument and open so many intellectual fronts that the analysis can become overly complicated. More important, a book workshop by design and necessity significantly slows down a junior scholar's publication schedule. The additional investment in the first book takes valuable time away from other important research and publication efforts, especially work on new articles 
and a second major project. This delay can create heavy opportunity costs that have serious consequences at tenure time. Because these potential downsides of book workshops have not received sufficient attention, this article provides a balanced assessment so that young scholars can thoroughly consider the pros and cons of holding such a feedback session. result, a beginning scholar may dilute a novel, provocative argument that runs up against the academic status-quo or cautiously weaken this innovative theory with plentiful qualifiers.

Even a battery of constructive suggestions and comments can make a theory overly complex and thus debilitate its central thrust. After all, experts look at issues from different perspectives

\section{As a result, a beginning scholar may dilute a novel, provocative argument that runs up against the academic status-quo or cautiously weaken this innovative theory with plentiful qualifiers.}

\section{BENEFITS OF BOOK WORKSHOPS}

An intense daylong discussion with well-selected specialists and other scholars who have read a manuscript normally yields an enormous amount of critical feedback and constructive ideas. Virtually all draft manuscripts have some gaps and problems, ranging from imprecision to overabundant detail and from oversimplification to excessive complexity. Books that emerge from dissertations can have particular issues-too much literature review, a tendency toward straw-manning, or excessive and exhausting detail in explaining intricate methodological procedures.

An additional round of comments, after all of the feedback that students receive from their dissertation committees and writers' groups, can identify and address these defects. Outside experts and scholars at the institution where a freshly minted PhD may hold a postdoc or (visiting) assistant professorship take a fresh look and bring new perspectives to bear. Their suggestions tend to enrich the project and induce a rethinking of potential peculiarities in the theoretical or methodological approach prevailing at the author's PhD-granting institution. These comments thus can prompt significant improvements in the final product. This higher quality, in turn, facilitates eventual publication and raises the academic stature and scholarly visibility of the author.

These are important and obvious benefits. Consequently, many junior scholars eagerly accept an institution's offer to hold a book workshop on their behalf. How could they turn down such a great opportunity to improve their first book? In life, however, few things are entirely positive and free of downsides and risks; in particular, opportunity costs often loom because time and energy are finite. Unfortunately, this mixed evaluation applies to book workshops as well. Therefore, junior scholars should think carefully about whether it is beneficial for them to proceed along this avenue. Does additional criticism really improve the quality of a dissertation book? Most important, will a book workshop further their career in a longer-term perspective, especially by heightening the chances of academic survival at tenure time?

\section{DOWNSIDES OF BOOK WORKSHOPS}

Regarding the manuscript examined at such a feedback session, there is a risk that "too many cooks may spoil the first book." Some experts may offer sustained criticism, especially when they encounter novel, counterintuitive arguments. After all, senior scholars tend to represent and defend the received wisdom and may see the claims of young upstarts as challenges to their own viewpoints and convictions. The penetrating vetting that they therefore may give a new argument can intimidate the target of this feedback, who lacks the thick skin of an old pachyderm. As a and may therefore forcefully advance their favorite explanatory factor at a book workshop. If an author tries to do justice to all these additional points and conditions, their own overall line of reasoning may lose clarity and may end up being hard to follow. Thus, a wealth of additional feedback can induce a young scholar to pack too much into a book and inadvertently lower its intellectual power and academic impact. Too many cooks can turn a clear broth with a distinctive flavor into a murky stew that is hard to swallow.

When a feedback session leads to this problem, reviewers commissioned by a university press to evaluate the resulting manuscript sometimes demand a substantial streamlining to eliminate these extraneous elements. Such a recommendation requires authors to undo changes that they introduced in response to a book workshop. This frustrating process of revisions and reverse revisions wastes a good amount of scarce and valuable time.

This risk of inefficiency points to a much more common and important pitfall: with its wealth of comments and criticisms, a book workshop creates substantial opportunity costs, which can have serious repercussions for an author's career advancement. After all, these feedback sessions are bound to affect a junior scholar's time management. Assistant professors, in particular, confront a rather fixed and firm deadline in their bid for the huge and decisive prize-namely, tenure. Therefore, they have strong incentives to allocate wisely their limited time.

By design, a book workshop directs time and energy toward the first post-dissertation project; in this way, it automatically takes away time from other research and publication efforts, especially work on a second project. Yet, from a career perspective, young scholars are well-advised not single-mindedly to maximize the quality of the first book but rather to employ a broader perspective and optimize the quantity, quality, and academic potential of their pre-tenure production overall. A wealth of additional feedback on the post-dissertation manuscript can distort this essential calculation and thus may end up endangering a beginning scholar's career advancement. Overinvestment in the first book can exact a serious price that may come to haunt the author at tenure time.

After all, a daylong book workshop is bound to yield an overabundance of comments and suggestions. The invited experts will always have interesting observations to make; from their perspective, there are angles and aspects that could be developed and gaps and problems that should be fixed. Commentators will feel compelled to justify their participation by offering ample feedback. Of course, the manuscript's author then feels obliged to address these comments-if only to avoid offending the outside experts, who have spent significant time preparing their suggestions and who may advance them with considerable emphasis. 
The additional round of revisions that the feedback from a book workshop requires can inadvertently jeopardize the author's academic career. This extra work takes a great deal of timeseveral months, if not longer. This added investment in the first book siphons off time and energy from other academic pursuits. Additional focus on the first book means significantly less dedication to other tasks, such as journal articles, which are crucial for demonstrating continuing productivity and intellectual progress.

\section{CAREER CONSIDERATIONS}

For these reasons, young scholars should think twice about holding a book workshop. It may be better to move the first book toward publication soon, even if the manuscript is not brilliant. Then junior academics can concentrate all of their time and energy on writing and publishing articles and on designing and researching a second book project-a difficult and time-consuming task. Given the stakes, it makes sense to justify this advice in greater depth.

First, publishing a book with a leading university press has not been that difficult in recent years, as the experiences of many new $\mathrm{PhDs}$ suggest. If the topic is relevant and interesting and if the scope of the analysis is not too narrow, an author usually can find a leading press that is willing to review the manuscript. Once this hurdle is overcome, the manuscript's chance of acceptance tends to be very high. After all, reviewers-even referees for top presses-rarely advocate outright rejection of a book manuscript; even when they demand extensive changes, the revised manuscript rarely seems to undergo a new round of external reviews. Note the enormous difference with top journals, where doubleblind peer review is very rigorous and where acceptance rates and recommendations. For these reasons, a book workshop is not required for guaranteeing the quality of a first book. Given the ample feedback received at the dissertation stage and then during the review process, a book workshop yields "diminishing returns"; its marginal benefit is comparatively limited.

By contrast, a workshop with outside experts can make a much more crucial contribution in the design and execution of a second major project or in the vetting of a set of articles that can give rise to such a major endeavor. In confronting this important task, scholars often are left to their own devices; they certainly cannot count on the structured support and sustained feedback provided by a dissertation committee. Moreover, most assistant professors end up teaching at institutions that have fewer experts in their specific area than their PhD-granting university. Due to size, salaries, teaching load, and fewer academic leaves, the new institution also may provide a less research-active environment. To compensate for these limitations, scholars can greatly benefit from inviting outside experts for a workshop on their second project, whether it is a book or a set of articles. Having external specialists participate in an intensive session tends to guarantee more instructive and pertinent feedback than they likely would receive at their new home institution.

The benefits of such a workshop on the second project stand out because alternative opportunities for obtaining suggestions and critiques have limitations. Paper presentations at professional conferences rarely lead to more than a few minutes of comments. Submitting pieces of a new major project in article form guarantees thorough and incisive feedback, but double-blind reviews tend to be skewed toward criticism and negativity. They rarely offer constructive suggestions, not to

\section{From a career perspective, it therefore makes sense for junior scholars to get their first book out soon and move on to other projects.}

hover below $10 \%$. Thus, compared to journal articles, it is much easier to publish a book.

From a career perspective, it therefore makes sense for junior scholars to get their first book out soon and move on to other projects. At tenure time, a university-press book counts as a crucial accomplishment. The book's acceptance or publication is usually sufficient for fulfilling an important promotion requirement, without penetrating scrutiny of its exact quality. Therefore, it is not prudent to overinvest in the first book. A book workshop can be overkill, and the longer-term consequences may end up "killing" the author at tenure time. Scarce time is best allocated to strategically more pressing efforts.

Second, although many comments offered at book workshops are helpful and constructive, this additional feedback is not that crucial for a beginning scholar. After all, first books emerge from dissertations, which presumably have already benefited from sustained guidance and ample, thorough comments by the author's doctoral committee and by graduate-student peers via dissertation-writers' groups. These critics have offered a wealth of suggestions and advice. Book manuscripts that arise from dissertations have been vetted so much that they are likely to be in fairly good shape. Moreover, the two or three reviewers commissioned by university presses provide another set of comments mention the brainstorming that can really help put an ambitious new project on track. Nothing is comparable to a halfday or daylong workshop, which provides ample feedback on existing ideas and research findings and which also allows for the open-ended, collective exploration of new angles, productive avenues, and exciting inspirations. Thus, feedback sessions indeed can be very beneficial-for a second project and scholars' subsequent endeavors.

\section{SPECIFIC RECOMMENDATIONS}

In highlighting that young scholars need to look beyond their first book and optimize their pre-tenure productivity overall, my advice is not to rush toward a second project before finishing the first book and shepherding it to publication. After completing the $\mathrm{PhD}$, researchers may be so sick and tired of their dissertation that they cannot bear making the revisions necessary for book publication; instead, they prefer to explore a new, initially more exciting project. After all, "the grass always looks greener on the other side of the fence": what new gems can junior scholars find in the area of their dissertation, which they have already plowed up and down for years? Therefore, a new idea may look infinitely more fascinating than the painful drudgery involved in turning their dissertation into a book. 
In light of this distaste, a book workshop may seem to be a useful commitment device for finally tackling the unpleasant but necessary task of preparing the thesis for publication. But is it really a solution for this version of "weakness of will"? This expedient merely "kicks the problem down the road." After all, the surplus of comments and criticisms received during a lengthy feedback session will require yet another round of substantial revisions. Then, where is the commitment device for accomplishing those modifications? Embracing a book workshop for motivational reasons merely postpones the day of reckoning; and, in the aggregate, of course, it augments the pain-by requiring even more revisions.

It is imperative to finish the first book soon. From a career perspective, it makes no sense to move toward a second project without giving priority to completing the dissertation book. First things first: "Everything has its time," as the Bible teaches. According to this sequential approach, it is crucial to get the first book published before making serious, time-consuming forays into a second project. Moreover, it is advisable to do so expeditiously, without unnecessary overinvestment. As explained previously, a book workshop often is not very helpful for this essential time management. For the same reasons, whereas a book workshop can signal an author's serious commitment to the project for job-market purposes, a much stronger signal is forgoing a workshop and submitting the manuscript to a university press for review.

Ultimately, each young scholar needs to decide on their own whether a book workshop is likely to yield net benefits for them and is worth the opportunity costs. Several important considerations should shape this evaluation. What matters most are the type and condition of their dissertation; their probable resilience to a sustained battery of criticisms and their capacity to turn objections into ideas for productive revisions; and the professional position that they hold, which affects their timeframe.

First, the closer the dissertation is to a strong, well-integrated, and well-crafted book manuscript, the less benefit (i.e., "value added") that a workshop likely will yield and the greater the risk of diluting the main argument or making it overly complex. Authors of three-article theses, by contrast, can profit substantially from an intensive feedback session, which can weave disparate parts may bring? Do they have the concentration, intellectual strength, and confidence to maintain control of their main argument and refrain from responding to a multitude of comments by "throwing in" a number of tangents and conditioning factors? Can they come up with doable revisions that address core objections without taking too much time? Scholars who tend toward self-doubt and anxiety-not uncommon among professionals who stand at the uncertain beginning of their fairly risky career-can become bogged down by the criticism advanced by senior authorities and even by a wealth of constructive suggestions. For them, a daylong feedback session may be paralyzing and create an enormous time sink.

Third, the institutional positions that young researchers hold affects their time horizon, thereby conditioning whether they can afford the opportunity costs of a book workshop. In this respect, a postdoc faces a more comfortable situation than an assistant professor, whose tenure clock is already ticking, inexorably. The type of institution matters as well. A tenure-track position at an R1 university, especially in a top10 department, creates a greater need for a high-quality book. Moreover, a manageable if not light teaching load combined with greater chances of obtaining sabbaticals and fellowships also provide more time for investing in the first book. These factors enhance the benefits of a workshop and, to some extent, mitigate its opportunity costs. Of course, at such institutions, the demands of making progress on a second project-if not to finish a second book-are high as well. The cost-benefit evaluation is more clear-cut for assistant professors at teaching institutions, where greater constraints on research time and less exacting standards of publication quality make it advisable to turn the dissertation into a book without the added detour of a long feedback session.

If after considering these factors and carefully weighing the pros and cons, junior scholars do decide to hold a book workshop, they should give considerable thought to how to structure it. In my view, less can be more: inviting several outside experts really runs the risk of "too many cooks spoiling the first book." Two outside specialists seem sufficient, plus the former dissertation adviser to provide counterbalance. Senior scholars have the broad perspective to highlight major theoretical themes, thereby enhancing a manuscript's overall caliber and appeal. Junior researchers may

\section{...for all of the emerging scholars who wrote their dissertation carefully and whose faculty committee provided substantial advice, feedback, and mentoring along the way, a book workshop seems unnecessary.}

into a coherent whole and, through collective brainstorming, design an overarching argument. Similarly, skimpy dissertations that resulted from a rush to meet a graduation deadline or to qualify for a job offer may well be in need of an additional round of comments and criticisms. However, for all of the emerging scholars who wrote their dissertation carefully and whose faculty committee provided substantial advice, feedback, and mentoring along the way, a book workshop seems unnecessary. Better to move on to the next project!

Second, do beginning scholars have the thick skin to not become demoralized by the frank criticism that a book workshop focus too much on smaller points and methodological details; on occasion, there even may be a certain risk of self-interested "turf" protection. "Less can be more" in another sense as well: the normal tendency when inviting outside experts is to commission them for a daylong feedback session. A four-hour workshop, by contrast, risks less "overkill," induces a focus on major issues, and yields a more manageable set of recommended revisions.

In summary, this article comprehensively assesses the academic value of book workshops by considering both the pros and cons. For this purpose, I question the "natural" assumption that such feedback sessions necessarily promise substantial net 
benefits for young scholars. It is crucial to consider carefully whether so much additional feedback for the first book is necessary. Even more important, authors need to keep in mind the opportunity costs of a book workshop: it takes time away from article production and progress on a second major project. Overinvestment in the first book can jeopardize the essential prize: tenure. Junior colleagues should always keep this overarching goal in mind. That way, they can be successful in their academic career!

\section{ACKNOWLEDGMENTS}

I thank Paul Chaisty, Eric Crahan, Austin Hart, Wendy Hunter, James Loxton, and two anonymous reviewers for important suggestions and comments. 